


\section{About IJMA [last updated October, $\left.1^{\text {st }}, 2021\right]$}

$\checkmark$ International Journal of Medical Arts is the Official Journal of the Damietta Faculty of Medicine, AlAzhar University, Egypt

$\checkmark$ It is an International, Open Access, Double-blind, Peer-reviewed Journal

$\checkmark$ Published four times a year

$\checkmark$ The First Issue was published in July 2019

$\checkmark$ Published under the following license: Creative Commons Attribution-ShareAlike 4.0 International Public License (CC BY-SA 4.0). It had updated from the Creative Commons license [CC BY] in volume 2, Issue 4, October 2020 About IJMA

$\checkmark$ The Egyptian Knowledge Bank hosts the web site of IJMA

$\checkmark$ The Egyptian Knowledge Bank supports IJMA

$\checkmark$ IJMA follows the regulations of the International Committee of Medical Journal Editors

$\checkmark$ IJMA is indexed in the "Directory of Open Access Journals" [15 January 2021].

$\checkmark$ IJMA is indexed in J-Gate [29-6-2021]

$\checkmark$ IJMA is a member of the International Society of Managing and Technical Editors

$\checkmark$ Listed in "Index Copernicus", "Publons", "Academic resource index [ResearchBib]" "Electronics journal library", "Eurasian Scientific Journal Index", "WorldCat" Superstar Journal Database, and "Citefactor"

$\checkmark$ IJMA introduced to the search engine [BASE] through DOAJ

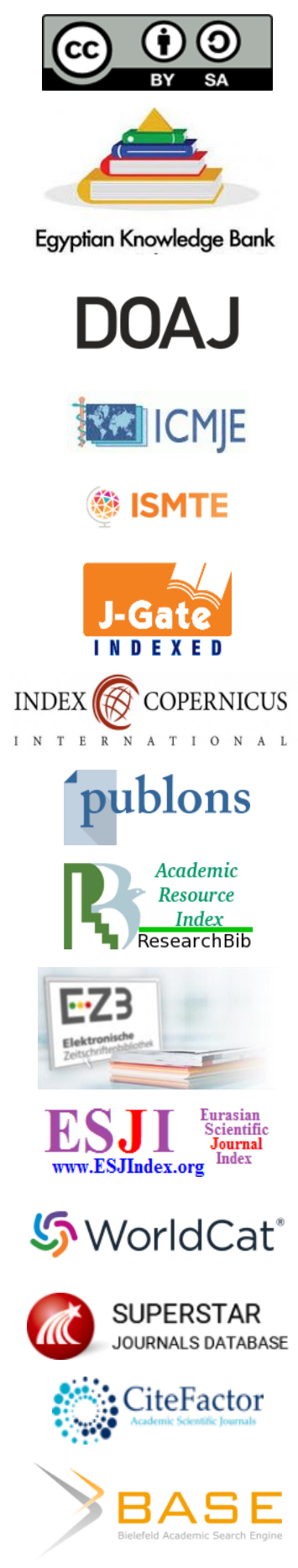




Available online at Journal Website
https://ijma.journals.ekb.eg/
Main subject [Pediatrics]

Original Article

\title{
Serum Carnitine Levels in Preterm Infants with Respiratory Distress Syndrome
}

\author{
Basma Mahmoud Ghoniem [1], Mohamed Ibrahim Elsamanoudy [2] \\ 1 Department of Pediatrics, Ministry of health, Egypt \\ 2 Department of Pediatrics, Damietta Faculty of Medicine, Al-Azhar University, Egypt \\ Corresponding author: Basma Mahmoud Ghoniem. \\ Email: basmaghoniem88@gmail.com
}

Submission date: May 19, 2021; Acceptance date: September 03, 2021

DOI: $10.21608 / / J M A .2021 .75951 .1313$

\section{ABSTRACT}

Background: Respiratory distress syndrome [RDS] is among the most common diseases in preterm infants. Numerous causes of RDS have been recently diagnosed and researchers have identified the presence of low serum carnitine in preterm infants with RDS.

The aim of this study: to evaluate serum carnitine levels in preterm infants with RDS

Patients and methods: Eighty preterm infants were divided into two groups; group 1 consisted of 50 preterm with RDS in the first $6 \mathrm{~h}$ of life constituted Group [A] as they were preterm infants with RDS with normal serum carnitine levels while Group $[B]$ represented infants with carnitine deficiency. Control group 2 consisted of 30 preterm infants without RDS in the first $6 \mathrm{~h}$ of life. All cases and their mothers included in the study were subjected to a thorough history taking, thorough clinical examination and measurement of serum carnitine.

Results: The cases groups had significantly lower serum L-carnitine than the controls group [ $25.56 \pm 11.14$ vs. $34.53 \pm$ 2.54], and carnitine deficiency in RDS cases [32\%]. Concerning weight, cases with carnitine deficiency had higher weight than cases with normal carnitine and control. With regard to clinical manifestations, there was a statistically significant difference between the cases subgroups in Down score indicting severe RDS in cases with carnitine deficiency. There was a statistically significant difference among cases subgroups regarding radiological findings. The cases with carnitine deficiency had worse X-ray, more need for surfactant therapy and MV than the cases with normal carnitine.

Conclusion: Preterm neonates with RDS were demonstrated to be associated with a significant reduction in carnitine level compared to RDS- free preterm ones.

Keywords: Neonatal; Respiratory distress syndrome; Pulmonary immaturity; Carnitine deficiency.

This is an open-access article registered under the Creative Commons, ShareAlike 4.0 International license [CC BY-SA 4.0] [https://creativecommons.org/licenses/by-sa/4.0/legalcode. 1802 [DOI: 10.21608/IJMA.2021.75951.1313].

* Main subject and any subcategories have been classified according to the research topic 


\section{INTRODUCTION}

Respiratory distress syndrome in neonates is a breathing disorder arising at, or shortly after birth $[<24 \mathrm{~h}]$ and increases in severity during the first $48 \mathrm{~h}$ of life ${ }^{[1]}$. The incidence of RDS is $92 \%$ for neonates born at $24-25$ weeks, $88 \%$ for those at $26-27$ weeks, $76 \%$ for those at 28-29 weeks and $57 \%$ for those at 30-31 weeks [2, 3]. RDS is caused by physiological and structural pulmonary immaturity. Inadequate levels of pulmonary surfactant compromise alveolar integrity, impeding normal gas exchange; resulting in atelectasis and decreased lung compliance [4]. RDS is diagnosed by a combination of clinical manifestations, laboratory analysis and chest radiography. Early diagnosis is of great importance so that interventional therapy, respiratory support and surfactant replacement could be carried out [5].

Carnitine, a nutrient normally synthesized from methionine and lysine in the hepatic and renal tissues, is responsible for transports of long-chain fatty acids [LCFA] across the mitochondrial membrane where they undergo beta-oxidation to produce energy. Carnitine deficiency decreases LCFA availability for oxidation with a subsequent LCFA accumulation in the cytosol and reduction in ketone and energy production. Other carnitine functions include the maintenance of adequate free coenzyme-A required for various metabolic pathways ${ }^{[6]}$.

Carnitine has been demonstrated to accelerate the maturation of fetal lungs in rabbits and treatment of pregnant rats with carnitine resulted in a significant increase in total phospholipids and dipalmitoylphosphatidylcholine levels in fetal rat lungs. Palmitoyl carnitine is a form of carnitine that has been reported to have properties as an surface active molecule or surfactant, and functions an intermediate in mitochondrial fatty acid oxidation, which could reduce the alveolar surface tension [7].

The effects of carnitine in preterm infants on nutritional or respiratory functions, specifically apnea were evaluated in a lot of clinical trials. Two prior researches have revealed that carnitine levels were decreased in infants with RDS in comparison with RDS free ones. It has formerly been revealed that L-carnitine and betamethasone combination significantly increases the dipalmitoyl-phosphatidylcholine content of the fetal lungs and significantly decrease in the possibility of RDS and mortality in premature newborns, compared with betamethasone only $[7]$.

\section{AIM OF THE WORK}

The aim of the current work is to find out the correlation among serum carnitine and respiratory distress syndrome in preterm neonates.

\section{PATIENTS AND METHODS}

The present study is a case-control study carried out in the neonatal intensive care unit [NICU] at Al-Azhar University Hospital of New Damietta in the period from 1st December 2018 to the end of October 2019; it included a total of 80 preterm infants who fulfilled the inclusion criteria in the period of the study. The preterm infants were divided into two groups; group 1 consisted of 50 preterm with RDS in the first $6 \mathrm{~h}$ of life, and control group 2 consisted of 30 preterm infants without RDS in the first 6 hours of life.

Preterm infants with a gestational age [GA] of 28-36 weeks and preterm infants who developed RDS in the first $6 \mathrm{~h}$ of life were all included. However, the study excluded infants with congenital pneumonia, sepsis, multiple congenital anomalies, infants who received blood transfusion, infants who received surfactants, mothers who received dexamethasone or mothers with chronic hypertension, eclampsia, diabetes, chorioamnionitis, multiple gestations and infants with perinatal hypoxia, fetal growth restriction, congenital malformations and inherited metabolic diseases were ruled out.

All cases included in the study were subjected to a thorough history taking, thorough clinical examination, routine investigations of CBC, arterial blood gas, CRP, Chest X-ray and measurement of L-Carnitine.

\section{Assay principle}

The principle of the used kit in the current study depended on an enzyme-linked immunosorbent assay [ELISA]. The plate was pre-coated with human LCarnitine antibodies. L-Carnitine present in the sample was added and bounded to antibodies coated on the wells and after that biotinylated human L-Carnitine antibody was added and bounded to L-Carnitine in the specimen. After that, Streptavidin-HRP was added and bounded to the biotinylated L-Carnitine antibodies. Following incubation, unbound Streptavidin-HRP was discarded throughout the washing step. The substrate solution is added after that and color develops in proportion to the amount of human L-Carnitine. The reaction ended following the addition of acidic stop solution, while absorbance was measured at $450 \mathrm{~nm}$. 


\section{Statistical methods}

Results were gathered, tabulated, statistically analyzed by IBM software and statistical package SPSS version 20 [Armonk, NY: IBM Corp, 2013]. Two kinds of statistics were carried out: descriptive statistics: e.g., percentage $[\%]$, mean $[x]$, standard deviation $[S D]$, range and analytic statistics: e.g. Students t-test is a test of significance used for comparison among two groups having quantitative variables, Mann-Whitney test is a test of significance utilized to compare among 2 groups having quantitative variables not normally distributed and a P-value of less than 0.05 was considered statistically.

\section{RESULTS}

Table [1] demonstrates that there was no significant difference found among the studied groups in terms of demographic data, however regarding subgroups, there was a statistically significant difference found among the cases with normal carnitine and carnitine deficient cases as regard weight, and there was a statistically significant difference found between carnitine deficient cases and the controls with regard to weight.

Table [2] demonstrates that there was a significant difference between the cases group and the controls as regard the mean serum L-carnitine [n mole/ml], cases had lower serum carnitine level than controls.

Table [3] demonstrates that there was a highly statistically significant difference between cases with normal carnitine and carnitine deficient cases concerning Down score.

Table [4] demonstrates that there was a highly statistically significant difference found among both groups concerning surfactant and respiratory support [mechanical ventilation, nasal CPAP].

Table [5] demonstrates that there was a statistically significant difference between cases with normal carnitine and carnitine-deficient cases in terms of radiological findings.

Table [1]: Comparison between Cases and Controls concerning demographic data

\begin{tabular}{|c|c|c|c|c|c|}
\hline & & $\begin{array}{c}\text { Cases with normal } \\
\text { carnitine [N=35] }\end{array}$ & $\begin{array}{c}\text { Carnitine- } \\
\text { deficient cases } \\
{[N=15]}\end{array}$ & $\begin{array}{c}\text { Control [Group 2] } \\
\qquad \mathrm{N}=30\end{array}$ & $P$ value \\
\hline \multirow[t]{2}{*}{ Gender [No., \%] } & Females & $16[45.7 \%]$ & $8[53.3 \%]$ & 22 [73.3\%] & 0.149 \\
\hline & Males & 19 [54.3\%] & $7[46.7 \%]$ & $8[26.7 \%]$ & \\
\hline \multirow[t]{2}{*}{ GA } & Mean $\pm S D$ & $31.91 \pm 2.38$ & $30.60 \pm 1.50$ & $31.90 \pm 1.52$ & 0.070 \\
\hline & & $A$ & B & $A$ & \\
\hline \multirow[t]{2}{*}{ Weight [kg] } & Mean \pm SD & $1.23 \pm 0.32$ & $1.53 \pm 0.49$ & $1.27 \pm 0.45$ & $0.021^{*}$ \\
\hline & & $A$ & B & $A$ & \\
\hline \multirow[t]{3}{*}{ Apgar score } & At $1 \mathrm{~min}$ & $5.46 \pm 1.04$ & $5.13 \pm 0.92$ & $5.73 \pm 0.69$ & 0.108 \\
\hline & & $A$ & B & $A$ & \\
\hline & At $5 \mathrm{~min}$ & $8.37 \pm 1.21$ & $8.20 \pm 1.21$ & $8.43 \pm 1.07$ & 0.816 \\
\hline Maternal age [y] & Mean $\pm S D$ & $26.7 \pm 3.8$ & $24.5 \pm 2.5$ & $25.4 \pm 3.8$ & 0.11 \\
\hline \multirow{2}{*}{\multicolumn{2}{|c|}{ Cesarean section [No., \%] }} & $17[48.6 \%]$ & $10[66.7 \%]$ & $5[16.6 \%]$ & $0.031^{*}$ \\
\hline & & $A$ & $A$ & B & \\
\hline
\end{tabular}

A, B: Similar letters indicates no statistically significant difference between each two groups and [ $\left.{ }^{*}\right]$ indicate a statistically significant difference between each two groups.

Table [2]: Comparison between cases and control concerning L-carnitine

\begin{tabular}{cccc}
\hline L- Carnitine [n mole/ml] & Cases group [n=50] & Control group [n=30] & P value \\
\hline $\begin{array}{c}\text { Serum carnitine level [n } \\
\text { mole/ml] mean } \pm \text { SD }\end{array}$ & $25.56 \pm 11.14$ & $34.53 \pm 2.54$ & $<0.001$ \\
\hline
\end{tabular}


Table [3]: Comparison between cases with normal carnitine and carnitine deficient cases as regard Down Score Shashidhar et al. [12]

\begin{tabular}{lcccc}
\hline & & Cases with normal carnitine & Carnitine-deficient cases & p value \\
\hline \multirow{2}{*}{ Down Score } & Mild: N [\%] & $6[17.1 \%]$ & $0[0 \%]$ & $<0.001$ \\
& Moderate: N [\%] & $27[77.1 \%]$ & $0[0 \%]$ & \\
& Severe: N [\%] & $2[5.7 \%]$ & $15[100 \%]$ & 0.005 \\
& Median [IQR] & $5[5-7]$ & $5[5-6]$ & \\
\hline
\end{tabular}

Table [4]: Comparison between cases with normal carnitine and carnitine-deficient cases as regard surfactant and respiratory support

\begin{tabular}{|c|c|c|c|c|c|}
\hline & & & $\begin{array}{l}\text { Cases with normal } \\
\text { carnitine }\end{array}$ & $\begin{array}{c}\text { Carnitine-deficient } \\
\text { cases }\end{array}$ & $\begin{array}{l}p \\
\text { value }\end{array}$ \\
\hline \multirow{3}{*}{\multicolumn{2}{|c|}{ Surfactant }} & No doses & 22 [62.9\%] & $2[13.3 \%]$ & \multirow{3}{*}{$<0.001$} \\
\hline & & 1 DOSE & 12 [34.3\%] & $6[40.0 \%]$ & \\
\hline & & $\stackrel{2}{2}$ & $1[2.9 \%]$ & $7[46.7 \%]$ & \\
\hline \multirow{2}{*}{\multicolumn{2}{|c|}{ Respiratory support }} & MV & $5[14.3 \%]$ & $11[73.3 \%]$ & \multirow{2}{*}{$<0.001$} \\
\hline & & NCAPAP & $30[85.7 \%]$ & $4[26.7 \%]$ & \\
\hline \multirow{2}{*}{\multicolumn{2}{|c|}{$\begin{array}{l}\text { Surfactant } \\
\text { support }\end{array}$}} & Yes & 19 [61.3\%] & $7[36.8 \%]$ & \multirow{2}{*}{0.010} \\
\hline & & No & $12[38.7 \%]$ & $12[38.7 \%]$ & \\
\hline
\end{tabular}

Table [5]: Comparison between cases with normal carnitine and carnitine deficient-cases regarding radiological finding

\begin{tabular}{lccc}
\multicolumn{1}{c}{ X-ray findings } & Cases with normal carnitine & Carnitine-deficient cases & P value \\
\hline RDS - air bronchogram & $14[40.0 \%]$ & $0[0 \%]$ & \\
\hline RDS - ground glass appearance & $12[33.3 \%]$ & $0[0 \%]$ & $<0.001$ \\
RDS - white lung & $9[25.7 \%]$ & $15[100 \%]$ & \\
\hline
\end{tabular}

\section{DISCUSSION}

RDS in neonates, is still a primary etiology of morbimortality in preterm infants and it is considered one of the main etiology of NICU admission [8]. Carnitine plays an essential role in $\beta$ oxidation as it transports long chain fatty acids across the mitochondrial membrane [9]. Reduction in neonatal serum carnitine levels in preterm infants with RDS throughout the first week of life, which may be due to the increasing consumption of carnitine in lung tissue for surfactant synthesis and may be owing to low levels of a-butyrobetaine hydroxylase, a catalyzing enzyme in the last step of the carnitine biosynthesis ${ }^{[7]}$.
With regard to demographic data, there was no statistically significant difference among cases and control groups, this came in agreement with Ozturk et al. [7] and Taman et al. [10] who reported no statistically significant difference between the cases and control regarding demographic data, While in subgroups, as regard weight, there was a statistically significant difference among cases with carnitine deficiency and cases with normal carnitine level, this agrees with Qi et al. [11], and Ozturk et al. [7] who reported that serum carnitine levels increased as birth weight reduced, but this disagrees with Taman et al. [10] that displayed no significant difference among groups in terms of weight. 
This difference may be due to the change in the day in which weight was measured.

As regard surfactant therapy, there was a significant increase in the requirement for surfactant therapy in preterm with carnitine deficiency as $86.7 \%$ of them needed one or more surfactant doses while $62.9 \%$ of preterm with normal serum carnitine level were not in need of surfactant therapy; our findings were in agreement with Ozturk et al. ${ }^{[7]}$ who reported that there were significant differences among study groups in terms of the number of surfactant therapy required.

Concerning respiratory support, there was a significant increase in the need for respiratory support especially mechanical ventilation in cases with carnitine deficiency $[73.3 \%$ of them was in need of MV while only $14.3 \%$ of preterm with normal serum carnitine level required MV]. Our findings were in agreement with Ozturk et al. ${ }^{7]}$ who reported that there was a significant difference among study groups regarding the need for MV and MV duration in experimental group than in the control group. Also, Said et al. ${ }^{[13]}$ recorded that, LCarnitine supplementation was associated with a significant reduction in the duration of stay on a mechanical ventilator.

Regarding the duration of hospitalization, the results of the present study showed that cases with carnitine deficiency stayed longer duration, that came in accordance with Said et al. [13] who reported that Lcarnitine supplementation was associated with a significant reduction in the duration of hospital stay.

Regarding L-carnitine serum levels, our results showed a significantly lower serum L-Carnitine levels among cases than control $[25.56 \pm 11.14$ vs. $34.53 \pm$ 2.54; $p$-value: $<0.001]$. These results came in the same line with Korkmaz et al. ${ }^{[14]}$ who reported in their study that the average neonatal plasma carnitine level was significantly lower in preterm infants with RDS in comparison with the controls, while the results of Ozturk et al. ${ }^{[7]}$ who reported that initial serum carnitine levels [in the first six hours of life] demonstrated insignificant reduction of serum carnitine and this disagreed with our results might be owing to a reduction in maternal fetal transfer of carnitine or increased consumption of carnitine in fetal lung tissue for surfactant biosynthesis which may be contributing factor in the context of RDS pathogenesis.

The frequency of carnitine deficiency in our study was $30.0 \%$, while in the control group no carnitine deficiency was observed, and $100.0 \%$ of preterm in the control group were having normal L-carnitine levels with a statistically significant difference between both groups $[P=0.001]$, the difference in the frequency of L-carnitine deficiency between the results of this study and Korkmaz et al. [14] may be due to environmental or economic factors and nutritional deficiency.

Regarding the correlation between serum carnitine level and other variables, as regard demographic data, there was no relation among carnitine level and gender, there was a negative correlation between carnitine level and GA, which agrees with Taman et al. ${ }^{[10]}$ who found a negative association between carnitine and GA. There was also a significant negative association between carnitine level and birth weight and positive correlation between L-carnitine level with APGAR score this which agree with Ozturk et al. ${ }^{[7]}$ who showed a negative correlation with birth weight and positive correlation with APGAR score and this is disagree with Taman et al. [10] who showed no significant correlation between serum carnitine, birth weight and APGAR score. There was no correlation between carnitine level maternal age or CS, which agrees with Taman et al. ${ }^{[10]}$.

\section{CONCLUSION}

The level of serum carnitine in preterm neonates with RDS was significantly lower than healthy preterm and carnitine deficiency in RDS cases [30\%] was more frequent than healthy neonates, with a statistically significant difference between cases and controls. Additionally, there was a statistically significant difference among cases subgroups and controls regarding carnitine level. The present study recommends measuring carnitine in preterm with RDS especially in severe degrees, further large- scaling for measuring carnitine in preterm with respiratory distress syndrome and trials of carnitine intake are required for deciding its role and maternal carnitine intake during pregnancy should be encouraged.

Financial and Non-financial Relationships and Activities of Interest

None

\section{REFERENCES}

1. Wang J, Liu X, Zhu T, Yan C. Analysis of neonatal respiratory distress syndrome among different gestational segments. Int J Clin Exp Med. 2015 Sep 15;8(9):16273-9. PMID: 26629144. 
2. Lovrenski J. Lung ultrasonography of pulmonary complications in preterm infants with respiratory distress syndrome. Ups J Med Sci. 2012;117(1):10-7. DOI: 10.3109/03009734.2011.643510.

3. Raimondi F, Rodriguez Fanjul J, Aversa S, Chirico G, Yousef N, De Luca D, et al. Lung Ultrasound for Diagnosing Pneumothorax in the Critically III Neonate. J Pediatr. 2016 Aug;175:74-78.e1. DOI: 10.1016/j. jpeds.2016.04.018.

4. Sweet DG, Carnielli V, Greisen G, Hallman M, Ozek E, Plavka $\mathrm{R}$, et al. European Consensus Guidelines on the Management of Respiratory Distress Syndrome 2016 Update. Neonatology. 2017;111(2):107-125. DOI: $10.1159 / 000448985$.

5. Hiles M, Culpan AM, Watts C, Munyombwe T, Wolstenhulme S. Neonatal respiratory distress syndrome: Chest X-ray or lung ultrasound? A systematic review. Ultrasound. 2017 May;25(2):8091. DOI: $10.1177 / 1742271 \mathrm{X} 16689374$.

6. Clark MA, Stein REK, Silver EJ, Khalid S, Fuloria M, Esteban-Cruciani NV. Carnitine deficiency in preterm infants: A national survey of knowledge and practices. J Neonatal Perinatal Med. 2017;10(4):381-386. DOI: 10.3233/NPM-16146.

7. Ozturk MA, Kardas Z, Kardas F, Gunes T, Kurtoglu S. Effects of L-carnitine supplementation on respiratory distress syndrome development and prognosis in premature infants: A single blind randomized controlled trial. Exp Ther Med. 2016 Mar;11(3):11231127. DOI: 10.3892/etm.2015.2964.

8. Read B, Lee DS, Fraser D. Evaluation of a practice guideline for the management of respiratory distress syndrome in preterm infants: A quality improvement initiative. Paediatr Child Health. 2016 JanFeb;21(1):e4-9. DOI: 10.1093/pch/21.1.5a.
9. Ramaswamy M, Anthony Skrinska V, Fayez Mitri R, Abdoh G. Diagnosis of Carnitine Deficiency in Extremely Preterm Neonates Related to Parenteral Nutrition: Two Step Newborn Screening Approach. Int J Neonatal Screen. 2019 Aug 31;5(3):29. DOI: $10.3390 /$ ijns 5030029 .

10. Taman KH, Zaki OK, Kheder MS, Rheem MAA. Measurment of Carnitine in Preterm Neonates Suffering Respiratory Distress Syndrome and the Effect of its Supplement. JSC. 2017; 20[4]. DOI: 10.21608/JSC.2019.51161

11. Qi ZY, Duan J, Wang Q, Yao Q, Zhong QH, Zhang $C Y$, Liang K. [Levels of blood free carnitine in preterm infants with different gestational ages and birth weights]. Zhongguo Dang Dai Er Ke Za Zhi. 2019 Jun;21(6):562-566. Chinese. DOI: 10.7499/j.issn.1008-8830.2019.06.012.

12. Shashidhar A, Suman Rao PN, Joe J. Downes score vs. Silverman Anderson score for assessment of respiratory distress in preterm newborns. Pediatr Oncall J. 2016;13[3]: 66-68. DOI:10.7199/ped.oncall. 2016.30

13. Said R, Abd El Meguid M, Mosallam D, Mahmoud M. 1003 Randomized Controlled Trial on Early LCarnitine Supplementation to Preterm Newborns with Respiratory Distress Syndrome. Does it Influence Neonatal Wellbeing? Arch Dis Childh. 2012;97 [Suppl 2]:A288. DOI: 10.1136/archdischild-2012302724.1003.

14. Korkmaz A, Tekinalp G, Coskun T, Yigit S, Yurdakok M. Plasma carnitine levels in preterm infants with respiratory distress syndrome. Pediatr Int. 2005 Feb;47(1):49-52. DOI: 10.1111/j.1442-200x.2005. 01998.x. 


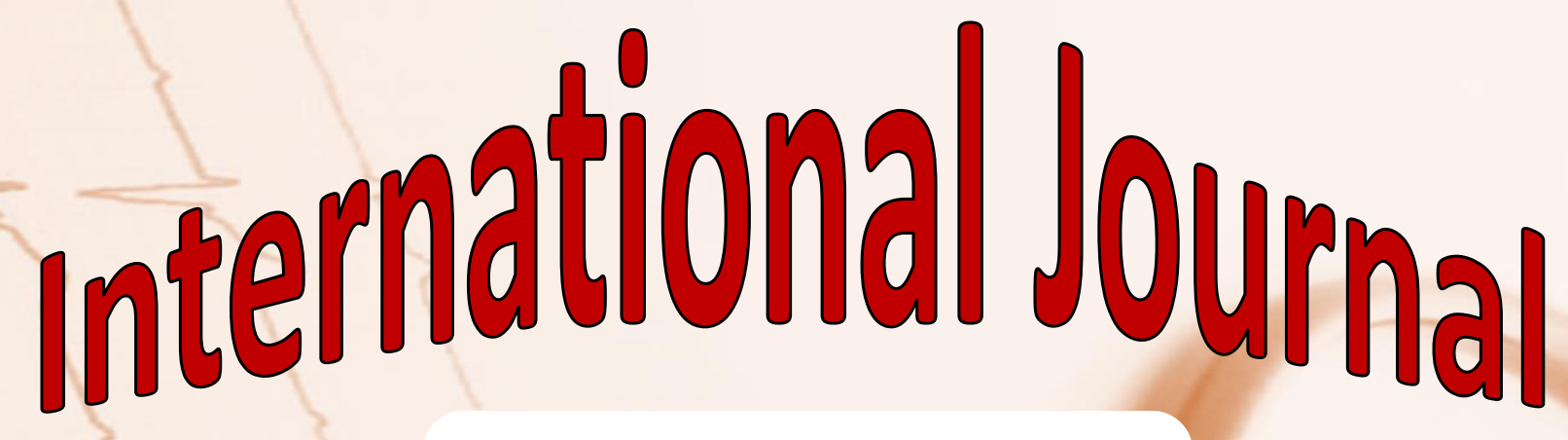

https://ijma.journals.ekb.eg/ Print ISSN: 2636-4174 Online ISSN: 2682-3780

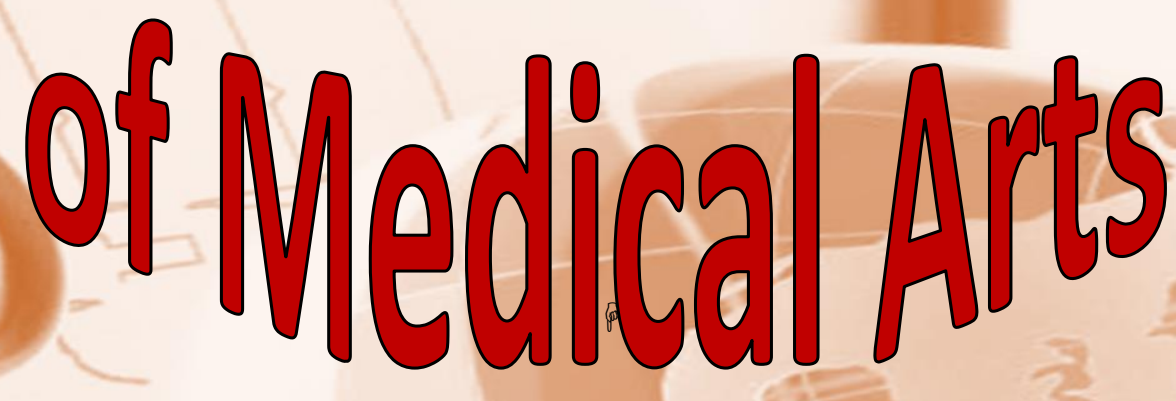

